\title{
Correction to: Impact of acute high-intensity interval exercise on plasma pentraxin 3 and endothelial function in obese individuals-a pilot study
}

\author{
Aaron L. Slusher ${ }^{1}\left[\right.$ : Brandon G. Fico ${ }^{2} \cdot$ Katelyn M. Dodge ${ }^{3} \cdot$ Ryan S. Garten $^{4} \cdot$ Peter J. Ferrandi $^{5}$. \\ Alexandra A. Rodriguez ${ }^{3}$. Gabriel Pena ${ }^{6}$. Chun-Jung Huang ${ }^{3}$
}

Published online: 20 May 2021

(c) Springer-Verlag GmbH Germany, part of Springer Nature 2021

\section{Correction to: European Journal of Applied Physiology https://doi.org/10.1007/s00421-021-04632-5}

The original version of this article unfortunately contained a mistake. The correct information is given below.

Article title should read as:

Impact of acute high-intensity interval exercise on plasma pentraxin 3 and endothelial function in obese individuals-a pilot study

In section "Correlational analysis among variables", second sentence should read as:

In addition, baseline plasma PTX3 concentrations were positively associated with PTX3 AUCi in response to HIIE ( $r=0.686, p=0.007$; Fig. 4a), whereas relative BAFMD, but not normalized BAFMD values, at baseline were negatively associated with the BAFMD response to acute HIIE, is indicated by $\mathrm{AUCi}(r=-0.549, p=0.042 ; r=-0.506$, $p=0.065$, respectively; Fig. 4b).

The original article has been corrected.

Publisher's Note Springer Nature remains neutral with regard to jurisdictional claims in published maps and institutional affiliations.

The original article can be found online at https://doi.org/10.1007/ s00421-021-04632-5.

Aaron L. Slusher

alslush@umich.edu

1 School of Kinesiology, University of Michigan, Ann Arbor, MI 48109, USA

2 Department of Kinesiology and Health Education, The University of Texas at Austin, Austin, TX 78712, USA

3 Exercise Biochemistry Laboratory, Department of Exercise Science and Health Promotion, Florida Atlantic University, Boca Raton, FL 33431, USA

4 Department of Kinesiology and Health Sciences, Virginia Commonwealth University, Richmond, VA 23284, USA

5 College of Graduate Health Sciences, The University of Tennessee Health Science Center, Memphis, TN 38163, USA

6 Department of Kinesiology, University of Maryland-College Park, College Park, MD 20742, USA 